\title{
Analysis of the Prognostic Effectiveness of a Multivisceral Resection for Locally Advanced Colorectal Cancer
}

\author{
Sejin Park, Yun Sik Lee \\ Department of Surgery, Wallace Memorial Baptist Hospital, Busan, Korea
}

Purpose: The aim of this study was to evaluate the prognostic effectiveness of multivisceral resections of organs involved by locally advanced colorectal cancer.

Methods: A retrospective study was performed to analyze the data collected for 266 patients who underwent a curative resection for pT3-pT4 colorectal cancer without distant metastasis from January 2000 to December 2007. Of these 266 patients, 54 patients had macroscopically direct invasion of adjacent organs and underwent a multivisceral resection. We evaluated the short-term and the long-term outcomes of a multiviceral resection relative to that of standard surgery.

Results: The most common location for the primary lesion was the rectum, followed by the right colon and the sigmoid colon. Among the combined resected organs, common organs were the small bowel, ovary, and bladder. In the multivisceral resection group, tumor infiltration was confirmed histologically in $44.4 \%$ of the cases while in the remaining patients, a peritumorous adhesion had mimicked tumor invasion. Postoperative complications occurred in $17.5 \%$ of the patients who underwent standard surgery vs. $35.2 \%$ of those who underwent a multivisceral resection $(\mathrm{P}<0.0001)$. But the survival rate of patients after a multivisceral resection was similar to that of patients after standard surgery (5-year survival rates: $61 \%$ vs. $58 \% ; \mathrm{P}=0.36$ ).

Conclusion: For locally advanced colorectal cancer, multivisceral resection was associated with higher postoperative morbidity, but the long-term survival after a curative resection is similar to that after a standard resection. Thus, a multivisceral resection can be recommended for most patients of locally advanced colorectal cancer.

\section{Keywords: Multivisceral resection; Locally advanced colorectal cancer}

\section{INTRODUCTION}

According to the annual report of the Cancer Registry of the Ministry for Health, Welfare and Family Affairs of Korea published in December 2009 [1, 2], colorectal cancer accounts of $12.7 \%$ of all cancers, and the trend is for an approximately $6.4 \%$ annual increase [1]. Because the life style in Korea has become westernized, the incidence of colorectal cancer is on the rise. The national program for the early detection of colorectal cancer, which

Received: August 31, 2010 Accepted: December 16, 2010

Correspondence to: Yun Sik Lee

Department of Surgery, Wallace Memorial Baptist Hospital, Namsan-dong,

Geumjeong-gu, Busan 609-728, Korea

Tel: +82-51-580-1288, Fax: +82-51-580-1292

E-mail:ysleewmbh@hanmail.net

(c) 2011 The Korean Society of Coloproctology

This is an open-access article distributed under the terms of the Creative Commons Attribution NonCommercial License (http://creativecommons.org/licenses/by-nc/3.0) which permits unrestricted noncommercial use, distribution, and reproduction in any medium, provided the original work is properly cited. is one of 5 major cancers in Korea, recommends that the guaiac test be performed annually on both males and females older than 50 years, and if an abnormality is detected, that perform colonoscopy or a double-contrast barium enema study be perfomed.

However, colorectal cancer is a disease preferentially occurring in the population older than 60 years. In Korea, it is diagnosed as symptomatic and advanced stage cancer in many cases rather than as early cancer through the use of an early diagnosis program for colorectal cancer [2]. Thus, it is usually diagnosed as locally advanced colorectal cancer, and tumor infiltration or adhesion is detected during surgery. Consequently, an en-bloc resection, a radical resection including adjacent organs and structures, is required [3-14].

In locally advanced colorectal cancer, when a multivisceral enbloc resection is selected, postoperative morbidity and an increase in mortality should be considered. Particularly, for elderly patients, patients whose risk level for surgery is high, and patients requiring a technically difficult combination of resections involving organs such as intrapelvic organs, the pancreas, etc., the decision to 
use a multivisceral resection must be made carefully $[3,4]$. In our study, the characteristics of patients who underwent a multivisceral resection for suspicious local infiltration to adjacent organs other than primary organs were examined, and the risks of a multivisceral resection and the difference in prognoses between a multivisceral resection and standard surgery were examined.

\section{METHODS}

From January 1, 2000, to December 31, 2007, a total of 356 colorectal cancer patients underwent surgery. Among pT3-pT4 stage patients, excluding patients with distant metastasis at the time of diagnosis, patients with recurrent or synchronous cancer, and patients who had undergone a palliative colostomy instead of a colon resection, 266 patients were examined retrospectively.

As preoperative diagnosis methods, colonoscopy, abdominal ultrasound, abdominal CT, etc. were applied, and all cases were operated on by a single surgeon using the open method. Clinicopathological findings were analyzed by using the hospital records, and follow-up information was obtainded from visits to outpatient clinics and telephone surveys.

The 266 patients were divided into a group of patients who did not have infiltration to adjacent organs and who underwent a standard resection (212 patients) and a group of patients who were suspected of having invasion to neighboring organs and who, thus, underwent a multivisceral resection (54 patients), and the age, gender, location of the primary lesion, tumor size, infiltration depth, stage, histological type and differentiation grade were analyzed. In addition, for cases in which tumor infiltration was suspected macroscopically, actual tumor infiltration was examined pathologically. In addition, the incidences of postoperative complications in the group that underwent a standard resection were analyzed and compared with those in the group that underwent a multivisceral resection, as were the 5-year survival rates. The stage of colorectal cancer was determined according to the classification of cancer disease stage of the 7th American Joint Committee on Cancer (AJCC) [15]. Postoperative complications and mortality were examined in a limited way during the hospital stay at the time of surgery only.

For all statistical analyses, the SPSS ver. 12.0 (SPSS Inc., Chicago, IL, USA) was used. For the comparison of variables, the unpaired $t$-test and the $\chi^{2}$-test were used. Survival rates were calculated by using the Kaplan-Meier method and the results were validated by using the log-rank test. A P-value less than 0.05 was considered to be statistically significant.

\section{RESULTS}

\section{Gender and age distributions}

The average age of the 266 patients was $63.8 \pm 12.1$ years, the mean age of the 212 patients who underwent a standard procedure was $63.7 \pm 12.4$ years, and the mean age of the 54 patients who under- went a multivisceral resection was $64.4 \pm 11.9$ years. The ratio of males to females was 1:0.97, the ratio for the group that underwent a standard resection being 1:0.98 and that for the group that underwent a multivisceral resection being 1:0.93. The gender ratios were not significantly different (Table 1).

\section{Distribution of tumors and histopathological characteristics}

As the site at which the primary tumor developed, the rectum was most prevalent, followed in order by the right large intestine, the sigmoid colon, the left large intestine, and the transverse colon.

Table 1. Clinicopathologic factors and multivisceral resection

\begin{tabular}{|c|c|c|}
\hline Characteristics & $\begin{array}{l}\text { Standard op. } \\
(\mathrm{n}=212)\end{array}$ & $\begin{array}{l}\text { Multiviceral op. } \\
\quad(n=54)\end{array}$ \\
\hline \multicolumn{3}{|l|}{ Age } \\
\hline Average: $63.8 \pm 12.2(\mathrm{yr})$ & $63.7 \pm 12.4$ & $64.4 \pm 11.9$ \\
\hline \multicolumn{3}{|l|}{ Gender } \\
\hline Male $(n=135)$ & $107(50.5)$ & $28(51.9)$ \\
\hline Female $(n=131)$ & $105(49.5)$ & $26(48.1)$ \\
\hline \multicolumn{3}{|l|}{ Location } \\
\hline Rectum $(n=130)$ & $99(46.7)$ & $31(57.4)$ \\
\hline Rt.colon $(n=67)$ & $55(25.9)$ & $12(22.2)$ \\
\hline Sigmoid colon $(n=41)$ & 35 (16.5) & $6(11.1)$ \\
\hline Lt.colon $(n=20)$ & $15(7.1)$ & $5(9.3)$ \\
\hline T-colon $(\mathrm{n}=8)$ & $8(3.8)$ & $0(0.0)$ \\
\hline \multicolumn{3}{|l|}{ Tumor size (maximum) } \\
\hline Average: $5.4 \pm 1.2(\mathrm{~cm})$ & $5.6 \pm 1.1$ & $6.2 \pm 1.3$ \\
\hline \multicolumn{3}{|l|}{ Depth of invasion } \\
\hline pT3 $(n=235)$ & $207(97.6)$ & $28(51.9)$ \\
\hline pT4 $(n=31)$ & $5(2.4)$ & $26(48.1)$ \\
\hline \multicolumn{3}{|l|}{ Stage } \\
\hline$\| A(n=112)$ & $96(45.3)$ & $16(29.6)$ \\
\hline$\| B(n=4)$ & $1(0.5)$ & $3(5.6)$ \\
\hline$\| C(n=10)$ & $0(0.0)$ & $10(18.5)$ \\
\hline IIIA $(n=0)$ & $0(0.0)$ & $0(0.0)$ \\
\hline IIIB $(n=94)$ & $87(41.0)$ & $7(13.0)$ \\
\hline$\| I I C(n=46)$ & $28(13.2)$ & 18 (33.3) \\
\hline \multicolumn{3}{|l|}{ Histologic grade } \\
\hline Adenocarcinoma $(n=244)$ & $195(92.0)$ & $49(90.7)$ \\
\hline Well differentiated $(n=58)$ & $44(20.8)$ & $14(25.9)$ \\
\hline Moderated differentiated $(n=166)$ & $136(64.1)$ & $30(55.5)$ \\
\hline Pooly differentiated $(n=20)$ & $15(7.1)$ & $5(9.3)$ \\
\hline Mucinous type $(n=20)$ & $16(7.5)$ & $4(7.4)$ \\
\hline Signet cell type $(n=2)$ & $1(0.5)$ & $1(1.9)$ \\
\hline
\end{tabular}

Values are presented as mean \pm SD or number (\%). 
The average tumor size of the group that underwent a standard procedure was $5.6 \pm 1.1 \mathrm{~cm}$, and that of the group that underwent a multivisceral resection was $6.2 \pm 1.3 \mathrm{~cm}$.

Among the 54 patients of the group that underwent a multivisceral resection, in 28 pT3 (52\%) cases, neighboring organ invasion was suspected macroscopically, so a multivisceral resection was performed. However, postoperative pathohistological findings showed only inflammatory adhesion to adjacent tissues without the penetration of cancer cells to the large intestine serosa; 26 pT4 (48\%) cases did show actual cancer cell invasion.

Based on the AJCC disease classification, stage IIA disease was detected in $16(29.6 \%)$ of the cases that underwent a multivisceral resection, stage IIB disease in 3 cases (5.6\%), stage IIC disease in 10 cases $(18.5 \%)$, stage IIIB disease in 7 cases $(13 \%)$, and stage IIIC disease in 18 cases $(33.3 \%)$. Stage IIIC disease was the most prevalent.

Regarding the histological morphology and differentiation of cells, an adenocarcinoma was found in 49 cases (90.7\%), a mucinous carcinoma in 4 cases (7.4\%), and a signet ring cell carcinoma in 1 case (1.9\%). An adenocarcinoma was the most prevalent. Among adenocarcinomas, a moderately differentiated adenocarcinoma was found in 30 cases (55.5\%), and it was the most preva-

Table 2. Organs of combined resection and pathologic cancer invasion

\begin{tabular}{|c|c|c|}
\hline Removed organs & $\begin{array}{l}\text { No. of patients } \\
\quad(n=54)\end{array}$ & $\begin{array}{l}\text { Pathologic cancer } \\
\text { invasion }(n=26)\end{array}$ \\
\hline Digestive system & $24(44.4)$ & $12(50)$ \\
\hline Small bowel ${ }^{\mathrm{a}}$ & $13(24.1)$ & $7(29.2)$ \\
\hline Duodenum & $2(3.7)$ & $1(4.2)$ \\
\hline Large bowel & $4(7.4)$ & $2(8.3)$ \\
\hline Liver & $4(7.4)$ & $2(8.3)$ \\
\hline Panceas & $2(3.7)$ & $1(4.2)$ \\
\hline Urinary system & $12(22.2)$ & $8(33.3)$ \\
\hline Bladder $^{\mathrm{a}}$ & $8(14.8)$ & $5(20.8)$ \\
\hline Ureter & $4(7.4)$ & $3(12.5)$ \\
\hline Kidney & $1(1.9)$ & $0(0.0)$ \\
\hline Female genital system & $13(24.1)$ & $4(16.7)$ \\
\hline Ovary $^{a}$ & $9(16.7)$ & $2(8.3)$ \\
\hline Uterus & $3(5.6)$ & $2(8.3)$ \\
\hline Vagina & $3(5.6)$ & $1(4.2)$ \\
\hline Male genital system & $4(7.4)$ & $1(4.2)$ \\
\hline Prostate & $2(3.7)$ & $1(4.2)$ \\
\hline Seminal vesicle & $2(3.7)$ & $0(0.0)$ \\
\hline Other & $8(14.8)$ & $4(16.7)$ \\
\hline Abdominal walla & $6(11.1)$ & $4(16.7)$ \\
\hline Spleen & $2(3.7)$ & $0(0.0)$ \\
\hline
\end{tabular}

Values are presented as number (\%).

aSome patients had more than one combined resection. lent.

\section{Multivisceral resection}

In the 54 patients who underwent a multivisceral resection, in regard to the organs removed, the small intestine was removed in 13 cases (24\%), which was the most prevalent, followed in order by the ovary and the bladder (Table 2 ). In cases showing actual cancer infiltration, the small intestine was most frequently resected in combination. In 45 cases, a multivisceral resection including one organ other than the primary lesion was performed, and in 11 cases, a multivisceral resection including more than two organs other than the primary lesion was performed.

\section{Postoperative complications}

In cases that underwent a standard procedure, postoperative complications developed in 37 patients (17.5\%), 40 events, and in cases that underwent a multivisceral resection, they developed in $19 \mathrm{pa}-$ tients (35.2\%), 21 events (Table 3). When the complications were divided into infectious complications and non-infectious complications, a trend was that both infectious and non-infectious complications occurred approximately 2 times more frequently in the patient group that had undergone a multivisceral resection, and the difference was statistically significant $(17.5 \%$ vs. $35.2 \%, \mathrm{P}<$

Table 3. Postoperative complications and operative death

\begin{tabular}{lcc}
\hline & $\begin{array}{c}\text { Standard op. } \\
(\mathrm{n}=212)\end{array}$ & $\begin{array}{c}\text { Multiviceral op. } \\
(\mathrm{n}=54)\end{array}$ \\
\hline Overall complications & $37(17.5)$ & $19(35.2)$ \\
Infectious complications $^{\mathrm{a}}$ & $19(9.0)$ & $9(16.7)$ \\
\hline Wound & $4(1.9)$ & $2(3.7)$ \\
Urinary tract infection & $1(0.5)$ & $1(1.9)$ \\
Abdominal abscess & $5(2.4)$ & $0(0.0)$ \\
Leakage & $2(0.9)$ & $1(1.9)$ \\
Pneumonia & $7(3.3)$ & $2(3.1)$ \\
\hline Bacteremia & $3(1.4)$ & $2(3.1)$ \\
Noninfectious complication & $18(8.5)$ & $12(22.2)^{\mathrm{a}}$ \\
\hline Obstruction & $2(0.9)$ & $5(9.3)$ \\
Urinary retention & $3(1.4)$ & $2(3.1)$ \\
\hline Liver dysfunction & $2(0.9)$ & $0(0)$ \\
Respiratory failure & $4(1.9)$ & $1(1.9)$ \\
Cardiac failure & $1(0.5)$ & $0(0.0)$ \\
Renal failure & $0(0.0)$ & $1(1.9)$ \\
Upper gastrointestinal bleeding & $0(0.0)$ & $1(1.9)$ \\
Wound seroma & $6(2.8)$ & $2(3.1)$ \\
Cerebral infarction & $0(0.0)$ & $1(1.9)$ \\
Operative death & $2(0.9)$ & $2(3.1)$ \\
\hline
\end{tabular}

Values are presented as number (\%).

a Some patients had more than one combined resection. 
Table 4. Stage-dependent 5-year survival in patients undergoing standard and multiviceral resection

\begin{tabular}{lccc}
\hline \multirow{2}{*}{ Stage } & \multicolumn{2}{c}{ 5-year survival rate (\%) } & \\
\cline { 2 - 3 } & $\begin{array}{c}\text { Standard op. } \\
(\mathrm{n}=212)\end{array}$ & $\begin{array}{c}\text { Multivisceral op. } \\
(\mathrm{n}=54)\end{array}$ & P-value \\
\hline$\|(\mathrm{n}=126)$ & 68 & 64 & 0.25 \\
III $(\mathrm{n}=140)$ & 56 & 52 & 0.38 \\
Over all & 61 & 58 & 0.36 \\
\hline
\end{tabular}

Table 5. Overall survival after multiviceral resection

\begin{tabular}{lccc}
\hline & $\begin{array}{c}\text { Inflammatory } \\
\text { infiltration }(\mathrm{n}=28)\end{array}$ & $\begin{array}{c}\text { Tumorous } \\
\text { infiltration }(\mathrm{n}=26)\end{array}$ & P-value \\
\hline 5-year survival rate $(\%)$ & 62 & 54 & 0.34 \\
\hline
\end{tabular}

0.001). Two postoperative deaths occurred in each group. In the group that underwent a standard procedure, one patient died of postoperative pneumonia and the other died of the leakage at the anastomosis site. In the group that underwent a multivisceral resection, one patient died of respiratory failure due to severe pleural effusion caused by renal failure and the other died of sepsis caused by a peritoneal abscess that developed due to the rupture of the tumors during surgery.

\section{Prognosis and survival rate}

In the group that underwent a standard procedure, the 5-year survival rate of stage II patients was $68 \%$, and that of stage III patients was $56 \%$. In the group that underwent a multivisceral resection, the 5-year survival rate of stage II patients was $64 \%$, and that of stage III patients was $52 \%$. In both groups, as the disease stage advanced, survival rates decreased (Table 4). In addition, the 5-year survival rate of the group that underwent a standard procedure was $61 \%$, and that of the group that underwent a multivisceral resection was $58 \%$, but the difference in survival rates was statistically not significant. In the group that underwent a multivisceral resection, the 5-year survival rate for patients who developed adhesion caused by simple inflammatory reactions was $62 \%$, and the 5-year survival rate of patients with adhesion caused by actual tumor infiltration was $54 \%$, but no statistically significant difference was shown (Table 5).

\section{DISCUSSION}

A multivisceral resection is defined as a surgical method resecting organs or structures adhering to the primary cancer en-bloc [4]. It has been reported that in colorectal cancer patients, cases in which local tumor invasion to adjacent organs or structures is suspected and in which a multivisceral resection is, thus, performed account for $7-16 \%$ of all cases $[4,6,7,16]$. In our cases, similarly, the ratio of patients undergoing a multivisceral resection was 54 of the 356 patients (15.2\%) who underwent surgery for colorectal cancer, which is comparable to the ratios reported by other studies.

Whether the adhesion to adjacent organs was caused by direct invasion by the tumor or as a result of a simple inflammatory reaction could not be determined by using macroscopic examination only, but it could be determined based on pathohistological findings after surgery. Among cases with adhesion of tumors to adjacent organs, $50-85 \%$ have been reported to be caused by actual cancer cell infiltration $[4,8-10,12,16]$. In our cases, 26 of 54 patients (48\%) had adhesion due to direct tumor infiltration, and the remaining 28 (52\%) had adhesion was caused by a simple inflammatory reaction. Thus, many studies have reported that in cases when operative findings show suspected tumor infiltration, a radical resection, an en-bloc resection including adjacent organs and structures, achieved a good treatment outcome [3-14].

When invasion of tumors to adjacent organs is suspected, the separation of the adhered organs from the tumors has been reported to induce dissemination of tumor cells, thus elevating the local recurrence rate. When tumors rupture during surgery performed to separating the tumors from adjacent organs, the 5-year survival rate is merely $17 \%$, but that of the en-bloc resection group is $49 \%$, so a noticeably poorer treatment outcome was achieved in the former $[4,9]$.

Izbicki et al. [13] reported studies conducted on $220 \mathrm{~T} 3$ and T4 colorectal cancer patients thought to have local tumor infiltration; a multivisceral resection was performed in 83 cases. Among those 83 cases, in 38 cases, tumor infiltration was suspected macroscopically; however, after final pathologic tests, inflammatory adhesion, not cancer invasion, was found. They stated that the median survival times of the group that underwent a standard procedure and the group that underwent a multivisceral resection were 45 months and 44 months, respectively, and that no differences in postoperative morbidity or mortality of the two resection groups were detected. Hence, for cases in which tumor infiltration is suspected, an aggressive multivisceral resection is required. In our cases, if high-risk surgery to perform an en-bloc resection or a highly technically difficult operation, for example, cases with adhesion to the pancreas or intrapelvic organs was not performed, an aggressive multivisceral resection was performed.

Lehnert et al. [4] analyzed 201 patients that underwent a multivisceral resection because of invasion of tumors to adjacent organs. The location of the primary tumor was the sigmoid colon in 65 cases $(32 \%)$, the rectum in 62 cases $(31 \%)$, and the right large intestine in 34 cases (18\%). In our cases, the rectum was the site in $57.4 \%$ of the cases, the right large intestine in $22.2 \%$, and the sigmoid colon in $11.1 \%$. The most prevalent organ was different from our study, but this is thought to be due to the fact that in upper rectal cancer cases, it is difficult to distinguish the organs from the sigmoid colon. However, the three organs where tumors developed most frequently were identical. Thus, for tumors that develop in the rectum, the incidence of invasion of malignant tumors to organs adjacent to the tumors has been shown to be high for tumors that develop in the right intestine and the sigmoid colon. Concern- 
ing adjacent organs to which tumors frequently adhere, Lehnert et al. [4] reported that in colorectal cancer cases, the organs were the large intestine and the bladder, and that in rectal cancer cases, they were, in order, the small intestine, the uterus, and the bladder. Gebhardt et al. [11] reported that the organs resected in combination were, in order, the small intestine, the bladder, and the female reproductive system. In our cases, the order was also the small intestine, the bladder, and the female reproductive system.

In the decision to use a multivisceral resection including adjacent organs, a fact that should be considered first is the increased morbidity and mortality after surgery. The incidence of complications after a multivisceral resection is reported to be from $11 \%$ to $44 \%$, with an average of approximately $31 \%[4,11-13,17-19]$. In regard to mortality, Gebhardt et al. [11] reported mortality in more than $3.6 \%$ of 173 patients. Cho et al. [3] reported that, among 36 patients, 1 patient died. In our cases, among 54 patients who underwent a multivisceral resection, 1 patient died. Among the 212 patients that underwent a standard procedure, 2 patients died.

Gebhardt et al. [11] reported that in colorectal cancer patients who underwent a multivisceral resection, the incidence of postoperative complications was $11.4 \%$, and that of mortality was $3.6 \%$, which were comparable to the rates of postoperative complications and mortality for our patient group that underwent a standard procedure (11.5\% and 3.4\%). Nakafusa et al. [19] investigated 323 pT3-pT4 colorectal cancer patients. A multivisceral resection was performed in 53 cases (16.4\%), and among them, cancer infiltration was detected in 28 cases (52.8\%). The incidences of postoperative complications in the group that underwent a standard procedure and the group that underwent a multivisceral resection were $17.8 \%$ and $49.1 \%$, respectively, and the incidences of infectious complications (11.1\% vs. $32.1 \%)$ and the incidences of noninfectious complications ( $8.9 \%$ vs. $20.8 \%$ ) were higher in the group that underwent a multivisceral resection. Lepape et al. [14] reported that in 41 colorectal cancer patients who underwent a multivisceral resection, the incidences of postoperative complications and mortality weres $30.9 \%$ and $12.5 \%$, respectively. In our study, in cases that underwent a multivisceral resection, 19 developed postoperative complications (35.2\%), and 2 died (3.7\%), results comparable to other studies.

Gebhardt et al. [11] reported that the effectiveness of a multivisceral resection is reflected in the survival rate. In the group that underwent a standard procedure and the group that underwent a multivisceral resection, the 5-year survival rates were examined for each stage, and the observed 5-year survival rates were as follows: stage II, $60 \%$ vs. $58 \%$; stage III, $41 \%$ vs. $43 \%$. Thus, for the same stage, no significant differences between the two surgery groups were shown. In addition, in the multivisceral resection group, the 5-year survival rates of $\mathrm{pT} 3$ patients with adhesion due to a simple inflammatory reaction and of pT4 patients with adhesion due to actual cancer infiltration weres $64 \%$ and $44 \%$, respectively, which was comparable to our study. In the results reported by Lehnert et al. [4] the 5-year survival rates of stage II patients in the group that underwent a standard procedure and in the group that underwent a multivisceral resection were $66 \%$ and $63 \%$, respectively, and those of stage III patients were $45 \%$ and $38 \%$. In a recent study conducted on a large number of patients, the 5-year survival rate after a multivisceral resection was been reported to be approximately $51 \%[4,10,11]$, which is similar to the result in our study. However, in the study reported by Nakafusa et al. [19], the 5-year survival rates of the group that underwent a standard procedure and of the group that underwent a multivisceral resection were $79.5 \%$ and $76.6 \%$, respectively, which are different from our study. This is thought to be due to the difference in the selection of patients, which excluded emergency surgery patients, the difference of stage at the time of surgery, etc.

In several studies, the effectiveness of a multivisceral resection has also been reported to be reflected in the rate of local recurrence and the disease-free survival rate. Croner et al. [20] reported that in 174 multivisceral resection patients, en-bloc resection of cancer could be performed in 162 patients (93.1\%), that the local recurrence rate after surgery was $6.5 \%$, and that the presence or absence of lymph node metastasis and the dissemination of cancer cells during surgery were major factors exerting effects. Nakafusa et al. [19] reported that the 5-year disease-free survival rate after surgery for the group that underwent a standard procedure (72.9\%) was not greatly different from that of the group that underwent a multivisceral resection (66.8\%). When prognostic factors were analyzed by using a multivariate analysis, tumor size, level of infiltration, volume of blood loss during surgery, operation time, and whether or not transfusion had been performed were found to be major prognostic factors. In our study, the number of subjects was small, and the follow-up observation period was short, so it was difficult to perform the follow-up observation. Thus, a multivariate analysis for the local recurrence rate and the disease-free survival rate could not be performed. However, in locally advanced colorectal cancer cases, $48 \%$ involved actual cancer infiltration, complications, although mild in most cases, were increased after a multivisceral resection, and the 5-year survival rate was not significantly different from that for a standard procedure. Thus, good outcomes may be obtained by performing a multivisceral resection aggressively.

For the treatment of locally advanced colorectal cancer that has invaded adjacent organs, radical surgery using a multivisceral resection has the disadvantage of increased postoperative complications, but the 5-year survival rate is comparable to that for the standard procedure. Therefore, except for patients with high risk, an aggressive multivisceral resection may increase the possibility of long-term survival after surgery.

\section{CONFLICT OF INTEREST}

No potential conflict of interest relvant to this article was reported. 


\section{REFERENCES}

1. Ministry for Health, Welfare and Family Affarirs. Annual report of cancer incidence (2007), cancer prevalence (2007), and survival (1993-2007) in Korea. Seoul: Ministry for Health, Welfare and Family Affairs; 2009.

2. Lee CR, Kim YW, Kim NK, Hur H, Min BS, Lee KY, et al. The influence of age on survival and recurrence after a curative surgical resection for colon cancer patients. J Korean Soc Coloproctol 2009;25:401-9.

3. Cho SW, Lee RA, Chung SS, Kim KH. Concomitant adjacent organ resection in locally advanced colon cancer. J Korean Soc Coloproctol 2009;25:94-9.

4. Lehnert T, Methner M, Pollok A, Schaible A, Hinz U, Herfarth C. Multivisceral resection for locally advanced primary colon and rectal cancer: an analysis of prognostic factors in 201 patients. Ann Surg 2002;235:217-25.

5. Nelson H, Petrelli N, Carlin A, Couture J, Fleshman J, Guillem J, et al. Guidelines 2000 for colon and rectal cancer surgery. J Natl Cancer Inst 2001;93:583-96.

6. Staniunas RJ, Schoetz DJ Jr. Extended resection for carcinoma of colon and rectum. Surg Clin North Am 1993;73:117-29.

7. Sugarbaker PH, Corlew S. Influence of surgical techniques on survival in patients with colorectal cancer. Dis Colon Rectum 1982; 25:545-57.

8. Eisenberg SB, Kraybill WG, Lopez MJ. Long-term results of surgical resection of locally advanced colorectal carcinoma. Surgery 1990;108:779-85.

9. Gall FP, Tonak J, Altendorf A. Multivisceral resections in colorectal cancer. Dis Colon Rectum 1987;30:337-41.

10. Heslov SF, Frost DB. Extended resection for primary colorectal carcinoma involving adjacent organs or structures. Cancer 1988;
62:1637-40.

11. Gebhardt C, Meyer W, Ruckriegel S, Meier U. Multivisceral resection of advanced colorectal carcinoma. Langenbecks Arch Surg 1999;384:194-9.

12. Sokmen S, Terzi C, Unek T, Alanyali H, Fuzun M. Multivisceral resections for primary advanced rectal cancer. Int J Colorectal Dis 1999;14:282-5.

13. Izbicki JR, Hosch SB, Knoefel WT, Passlick B, Bloechle C, Broelsch CE. Extended resections are beneficial for patients with locally advanced colorectal cancer. Dis Colon Rectum 1995;38:1251-6.

14. Lepape A. Prevention of nosocomial infections in ICU. What is really effective? Med Arh 2003;57(4 Suppl 1):15-8.

15. Edge SB, Byrd DR, Compton CC, Fritz AG, Greene FL, Trotti A, editors. AJCC cancer staging manual. 7th ed. New York: Springer; 2009.

16. Kruschewski M, Pohlen U, Hotz HG, Ritz JP, Kroesen AJ, Buhr HJ. Results of multivisceral resection of primary colorectal cancer. Zentralbl Chir 2006;131:217-22.

17. Luna-Perez P, Rodriguez-Ramirez SE, De la Barrera MG, Zeferino M, Labastida S. Multivisceral resection for colon cancer. J Surg Oncol 2002;80:100-4.

18. Eisenberg SB, Kraybill WG, Lopez MJ. Long-term results of surgical resection of locally advanced colorectal carcinoma. Surgery 1990;108:779-85.

19. Nakafusa Y, Tanaka T, Tanaka M, Kitajima Y, Sato S, Miyazaki K. Comparison of multivisceral resection and standard operation for locally advanced colorectal cancer: analysis of prognostic factors for short-term and long-term outcome. Dis Colon Rectum 2004;47:2055-63.

20. Croner RS, Merkel S, Papadopoulos T, Schellerer V, Hohenberger W, Goehl J. Multivisceral resection for colon carcinoma. Dis Colon Rectum 2009;52:1381-6. 